\title{
Intrauterine inflammation alters cardiopulmonary but not cerebral hemodynamics during open endotracheal tube suction in preterm lambs
}

Robert Galinsky', Timothy J.M. Moss ${ }^{1,2}$, Graeme R. Polglase ${ }^{1,2}$ and Stuart B. Hooper ${ }^{1,2}$

BACKGROUND: Intrauterine inflammation adversely affects cardiopulmonary, systemic, and cerebral hemodynamics in preterm neonates, but its impact on responses to endotracheal tube (ETT) suction, known to affect hemodynamics, is unknown. We hypothesized that intrauterine inflammation would alter the cardiopulmonary and cerebral hemodynamic response to open ETT suction in preterm lambs.

METHODS: Chronically instrumented fetuses received intraamniotic lipopolysaccharide (LPS; to induce intrauterine inflammation) or saline at $118 \mathrm{~d}$ of gestation (term $\sim 147 \mathrm{~d}$ ). At $125 \mathrm{~d}$ of gestation, lambs were delivered and mechanically ventilated. Open ETT suction was performed $30 \mathrm{~min}$ after delivery. Pulmonary and cerebral arterial pressures and flows were recorded continuously.

RESULTS: Intrauterine inflammation reduced pulmonary blood flow (PBF) and increased pulmonary vascular resistance (PVR) after preterm birth. PBF and left-ventricular output (LVO) increased during and immediately after ETT suction in both groups, but the values were higher in LPS-exposed lambs. Preductal oxygenation significantly decreased during ETT suction but to a greater extent in LPS-exposed lambs. Cerebral blood flow and systemic arterial pressure were increased by open ETT suction similarly in the two groups.

CONCLUSION: Intrauterine inflammation exacerbates the neonatal hemodynamic response to open ETT suction.

ntrauterine inflammation is a common antecedent of preterm birth (1). Experimental and clinical evidence show that the cardiopulmonary and systemic circulations are adversely affected in preterm neonates exposed to intrauterine inflammation (2-5). This is probably caused by inflammationinduced impairment in pulmonary and systemic vascular development and function (4,6-11). Consequently, affected infants are more likely to suffer from inflammation-induced pulmonary hypertension, chronic lung disease, and disrupted cerebral perfusion, resulting in cerebral injury and poor neurological outcome $(2,4,5,12,13)$.

Many preterm infants exposed to intrauterine inflammation are also exposed to cardiovascular stressors during respiratory support provided in the neonatal period $(14,15)$. Endotracheal tube (ETT) suction is one of the most common interventions performed during respiratory support of preterm infants and is known to alter lung mechanics and systemic hemodynamics $(3,16-20)$. However, to our knowledge, the impact of prior exposure to intrauterine inflammation on these consequences is unknown.

Our aim was to examine the effect of open ETT suction on the compromised hemodynamic systems of preterm neonates born after exposure to intrauterine inflammation. Specifically, we focused on the effects of open ETT suction on cardiopulmonary and cerebral hemodynamics during ventilation of preterm lambs. We hypothesized that intrauterine inflammation would exacerbate the adverse cardiopulmonary and cerebral circulatory effects of open ETT suction in preterm lambs.

\section{RESULTS}

Birth weights of preterm lambs and the ratios of males to females were not different between the groups (Table 1). $\mathrm{PaO}_{2}$ and $\mathrm{PaCO}_{2}$, arterial oxygen saturation, alveolar arterial difference in oxygen $\left(\mathrm{AaDO}_{2}\right)$, oxygenation index $(\mathrm{OI}), \mathrm{pH}$, and lactate levels at birth did not differ between the groups (Table 1).

\section{Hemodynamics and Oxygenation After Preterm Birth}

Pulmonary blood flow (PBF) and left-ventricular output (LVO) were lower in lipopolysaccharide (LPS)-exposed lambs than in controls ( $P=0.04$ and 0.02 , respectively; Table 2$)$ before open ETT suction. End-diastolic PBF was lower in LPS-exposed lambs than in controls $(P=0.03$; Table 2). Pulmonary arterial pulsatility index $(\mathrm{PI})$ tended to be lower in LPS lambs $(P=0.06$; Table 2). Main pulmonary arterial pressure $\left(P_{\mathrm{MPA}}\right)$ did not differ between the groups $(P=0.7$; Table 2$)$. Carotid blood flow was $11.7 \pm 2.8 \mathrm{ml} / \mathrm{min} / \mathrm{kg}$ higher in LPS-exposed lambs than in controls, but this did not reach statistical significance $(P=$ $0.12)$. Carotid arterial PI and brachiocephalic arterial pressure $\left(P_{\mathrm{BCA}}\right)$ did not differ between the groups $(P=0.22$ and 0.99 , respectively; Table 2). Heart rate (HR) and preductal oxygen saturation were not different between the groups before open ETT suction ( $P=0.9$ and 0.6 , respectively; data not shown). 
Preductal Oxygenation and HR During and After ETT Suction In LPS-exposed lambs, a greater reduction in arterial oxygen saturation occurred at the end of open ETT suction and $10 \mathrm{~s}$ after suction, relative to controls ( $P<0.01$; Figure 1a). HR increased to a similar degree in both groups at the end of open ETT suction and $10 \mathrm{~s}$ after suction was completed $(P=0.03$; two-way ANOVA; Figure 1b).

\section{Cardiopulmonary Hemodynamics During and After ETT Suction} In LPS-exposed lambs, greater increases in PBF and LVO were observed, relative to controls, during and immediately after open ETT suction $(P<0.05$; Figure 2a,b). In relation to presuction values, $P_{\mathrm{MPA}}$ values in the LPS-exposed group were 22 and $24 \%$ higher than in the control group at the end of ETT suction

Table 1. Body weight, ratios of males to females and singletons to twins, arterial oxygenation, and acid-base status before ETT suction in control and LPS-exposed lambs

\begin{tabular}{lcc}
\hline & Control & LPS \\
\hline Body weight $(\mathrm{kg})$ & $2.84 \pm 0.14$ & $2.99 \pm 0.27$ \\
Male:female & $2: 2$ & $5: 1$ \\
Singleton:twin & $3: 1$ & $2: 4$ \\
Arterial oxygenation and acid-base status before ETT suction & \\
$\mathrm{PaO}_{2}(\mathrm{mmHg})$ & $38.7 \pm 4.9$ & $32.1 \pm 3.7$ \\
$\mathrm{SaO}_{2}(\%)$ & $81.4 \pm 9.2$ & $84.8 \pm 4.1$ \\
$\mathrm{AaDO}_{2}$ & $95.7 \pm 26.2$ & $82.4 \pm 20.7$ \\
$\mathrm{Ol}$ & $6.0 \pm 0.6$ & $8.3 \pm 1.1$ \\
$\mathrm{CO}_{2}(\mathrm{mmHg})$ & $31.1 \pm 4.3$ & $41.5 \pm 5.2$ \\
$\mathrm{pH}^{\mathrm{Lactate}}$ & $7.36 \pm 0.04$ & $7.35 \pm 0.05$ \\
$(\mathrm{mmol} / \mathrm{l})$ & $1.9 \pm 0.3$ & $2.3 \pm 0.5$ \\
\hline
\end{tabular}

Values are mean \pm SEM.

$\mathrm{AaDO}_{2}$, alveolar arterial difference in oxygen; ETT, endotracheal tube; LPS, lipopolysaccharide; Ol, oxygenation index; $\mathrm{SaO}_{2}$, arterial oxygen saturation.

Table 2. Cardiopulmonary and cerebral hemodynamic measurements after preterm birth, 2 min before the onset of open ETT suction in control and LPS-exposed preterm lambs

\begin{tabular}{lccc}
\hline & Control & LPS & Pvalue \\
\hline $\mathrm{PBF}(\mathrm{ml} / \mathrm{min} / \mathrm{kg})$ & $79.1 \pm 10.7$ & $48.31 \pm 5.6$ & $0.02^{*}$ \\
$\mathrm{LVO}(\mathrm{ml} / \mathrm{min} / \mathrm{kg})$ & $191.5 \pm 25.3$ & $124.6 \pm 16.6$ & $0.03^{*}$ \\
$\mathrm{PaPI}$ & $3.0 \pm 0.4$ & $1.9 \pm 0.1$ & 0.06 \\
$\mathrm{End}-$ diastolic PBF $(\mathrm{ml} / \mathrm{min} / \mathrm{kg})$ & $33.02 \pm 4.8$ & $21.5 \pm 3.3$ & $0.04^{*}$ \\
$P_{\text {MPA }}(\mathrm{mmHg})$ & $44.2 \pm 4.6$ & $46.7 \pm 3.7$ & 0.71 \\
$\mathrm{CaBF}(\mathrm{ml} / \mathrm{min} / \mathrm{kg})$ & $14.4 \pm 2.4$ & $26.1 \pm 5.1$ & 0.12 \\
$\mathrm{CaPI}$ & $2.3 \pm 0.3$ & $2.0 \pm 0.1$ & 0.22 \\
$P_{\mathrm{BCA}}(\mathrm{mmHg})$ & 48.7 & 48.6 & 0.99 \\
\hline
\end{tabular}

Values are mean \pm SEM

CaBF, carotid blood flow; CaPI, carotid arterial pulsatility index; ETT, endotracheal tube; LPS, lipopolysaccharide; LVO, left-ventricular output; PaPI, pulmonary arterial pulsatility index; $P_{B C A^{\prime}}$ brachiocephalic arterial pressure; $P B F$, pulmonary blood flow; $P_{\mathrm{MPA}^{\prime}}$ main pulmonary arterial pressure.

${ }^{*} P<0.05$ control vs. LPS and $10 \mathrm{~s}$ after suction, respectively $(P=0.08$; Figure $2 \mathrm{c})$. PI in the left pulmonary artery was reduced during and immediately after ETT suction in both groups $(P<0.05$; Figure $2 d)$.

\section{Cerebral Hemodynamics During and After ETT Suction}

Carotid blood flow and $P_{\mathrm{BCA}}$ were increased during and after open ETT suction $(P<0.001$ and 0.01 , respectively; Figure 3$)$ similarly in the two groups. Carotid arterial PI was reduced during and after open ETT suction $(P<0.0001$; Figure 3$)$, but no difference was observed between the groups.

\section{DISCUSSION}

We investigated the effect of intrauterine inflammation on cardiopulmonary hemodynamics after the initiation of ventilation in preterm lambs, and the cardiopulmonary hemodynamic response to open ETT suction. After preterm delivery, LPS-exposed preterm lambs had higher pulmonary vascular resistance (PVR) and lower PBF and LVO as compared with controls. Open ETT suction caused a greater increase in PBF, LVO, and a trend toward higher pulmonary arterial pressure in LPS-exposed lambs as compared with controls. Furthermore, open ETT suction caused a greater reduction in preductal oxygen saturation in LPS-exposed preterm lambs.

The reduction in PBF and LVO and increased PVR (as evidenced by reduced end-diastolic PBF) observed in LPSexposed lambs before ETT suction is consistent with previous clinical and experimental data $(2,4)$ and is probably associated

\section{a}

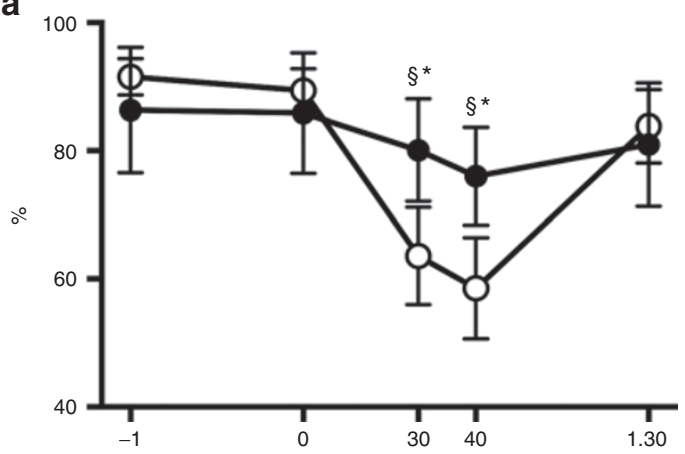

b

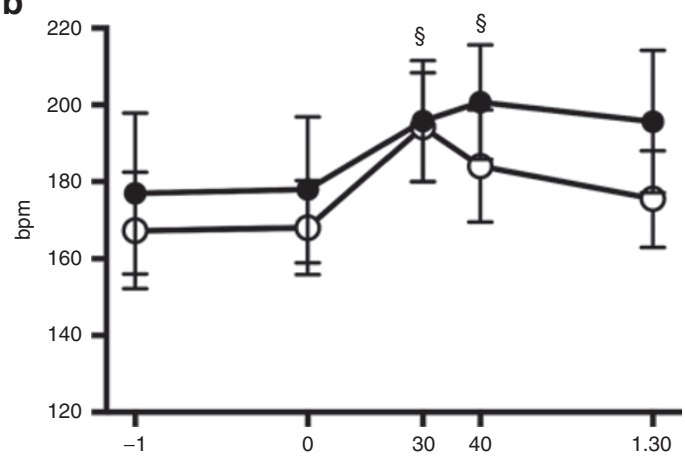

Figure 1. Oximetry and heart rate. (a) Oxygen saturation and (b) heart rate in control (solid circles) and lipopolysaccharide (LPS)-exposed preterm lambs (open circles) before, during, and after endotracheal tube suction. Data are mean \pm SEM. ${ }^{*} P<0.05$ LPS vs. control; ${ }^{\S} P<0.05$ for both groups relative to baseline (0). bpm, beats per minute. 
a

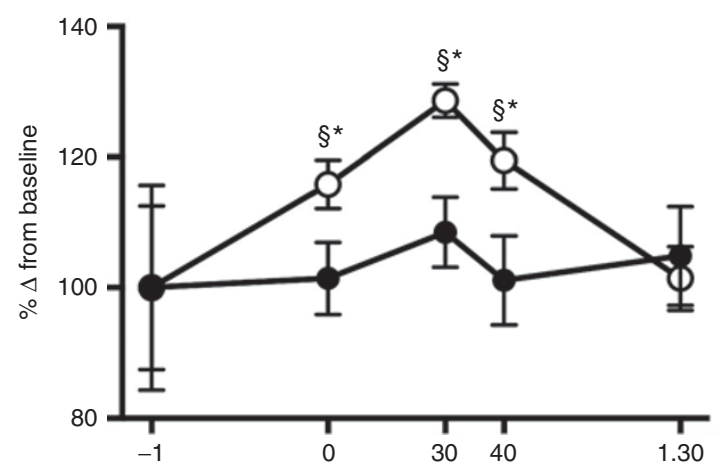

b

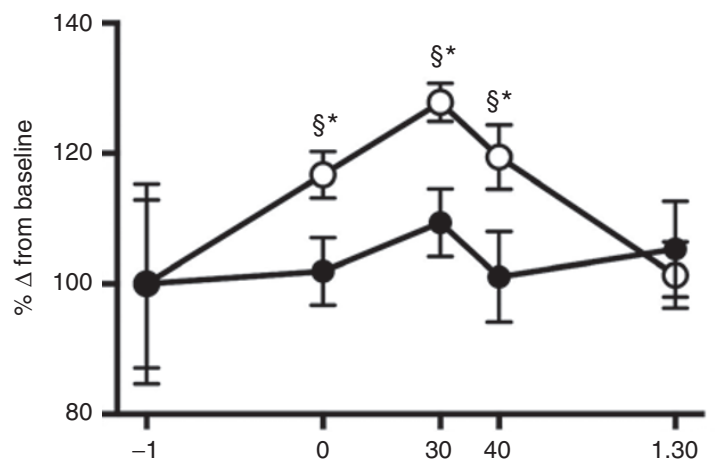

C

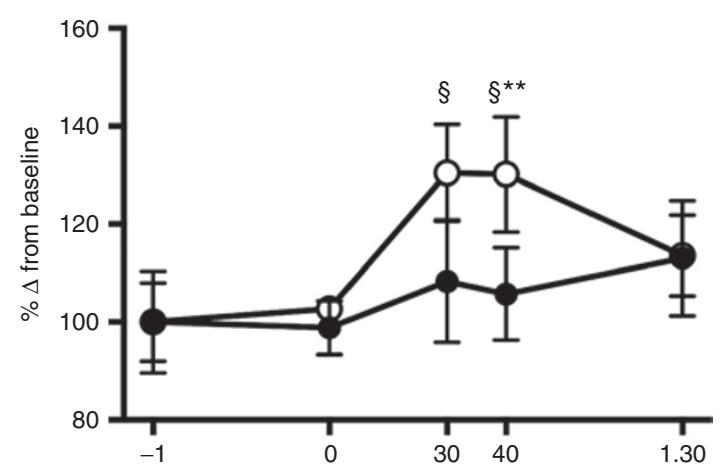

d

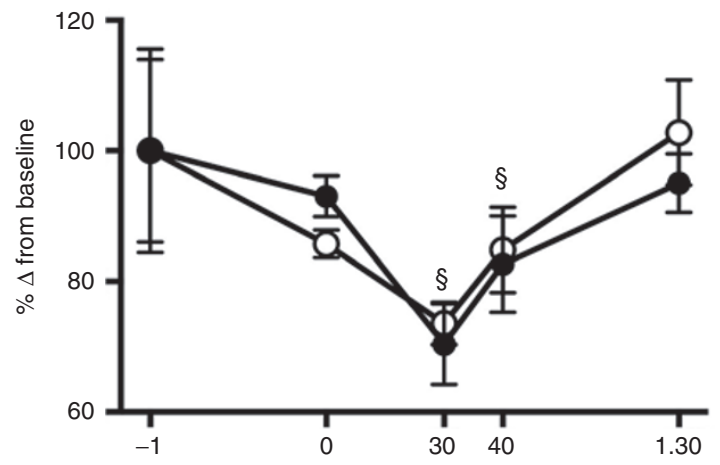

Figure 2. Cardiopulmonary hemodynamics. (a) Pulmonary blood flow, (b) left-ventricular output, (c) main pulmonary arterial pressure, and (d) pulmonary arterial pulsatility index, in control (solid circles) and lipopolysaccharide (LPS)-exposed preterm lambs (open circles) before, during, and after endotracheal tube suction. Data are mean \pm SEM. ${ }^{*} P<0.05$ LPS vs. control; ${ }^{5} P<0.05$ for both groups relative to baseline $(0) ;{ }^{* *} P=0.08$ LPS vs. control.

with impaired growth and development of the pulmonary vascular bed. Indeed, $7 \mathrm{~d}$ after intra-amniotic LPS exposure, fetal sheep have increased pulmonary arteriole hypertrophy a

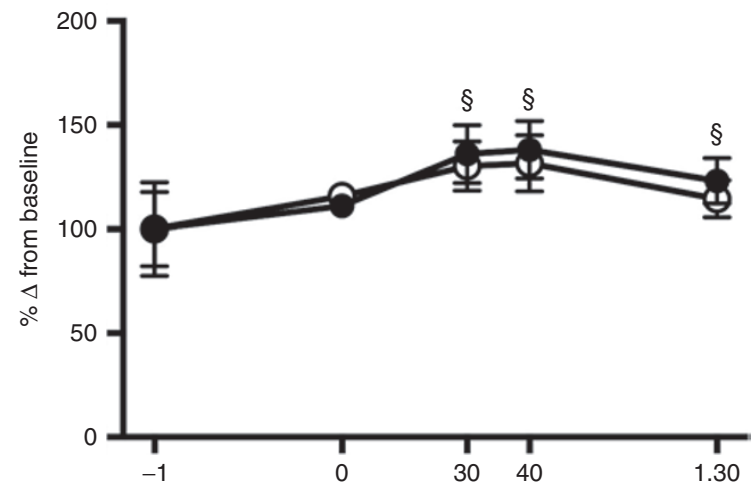

b

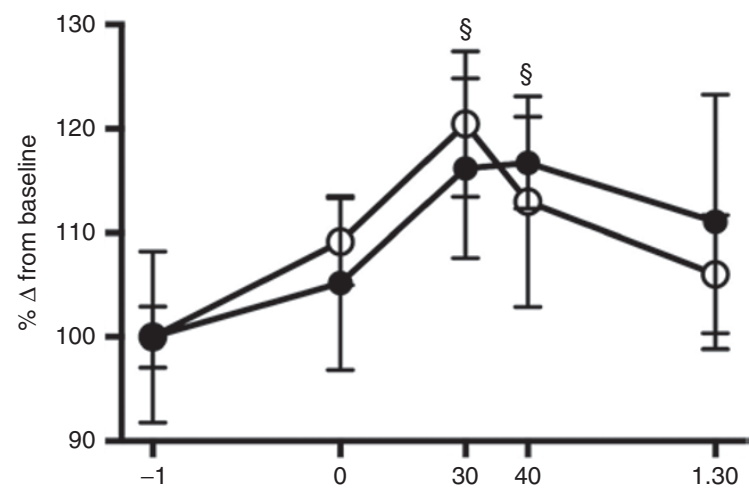

C

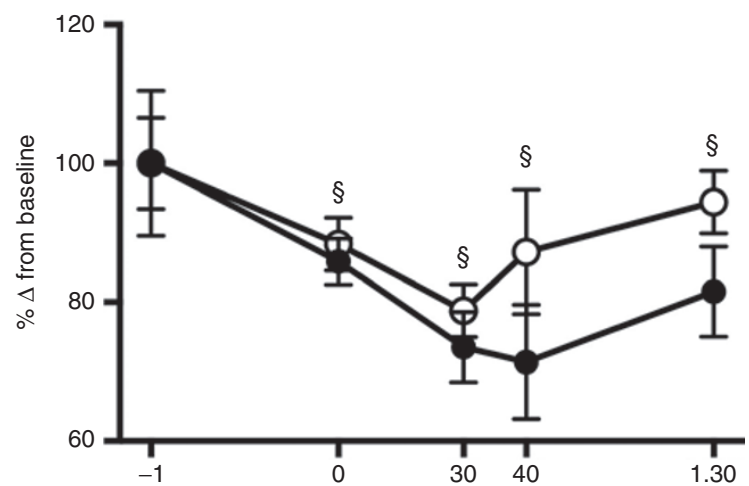

Figure 3. Cerebral hemodynamics. (a) Brachiocephalic arterial pressure, (b) carotid blood flow, and (c) carotid arterial pulsatility index in control (solid circles) and lipopolysaccharide-exposed preterm lambs (open circles) before, during, and after endotracheal tube suction. Data are mean \pm SEM. ${ }^{\circledR} P<0.05$ for both groups relative to baseline (0).

and reduced pulmonary vascular development and compliance. This is indicated by a reduction in the expression of vascular growth factors, increased fibrosis in the adventitial layer of pulmonary arterioles, and reduced endothelial nitric oxide synthase expression $(7,8)$.

During and immediately after open ETT suction, we observed a reduction in PVR, as evidenced by a reduction in PI within the left pulmonary artery. A strong relationship exists between alterations in airway pressure and PVR. In the neonatal and adult lung, an increase in airway pressure causes an increase in PVR and a subsequent reduction in PBF (21-24). Exposure to intrauterine inflammation accentuated the increase in PVR and reduction in PBF caused by increasing airway pressure in 
preterm lambs (2). Conversely, in fetal sheep, a reduction in airway pressure reduces PVR and increases PBF $(22,25)$. This may be associated with decreased intraluminal (alveolar) pressure, which increases the alveolar/capillary transmural pressure, as has previously been demonstrated in fetal and neonatal sheep $(22,25)$. Although the magnitude of reduction in PVR was similar between the groups, this induced a greater increase in PBF and LVO in LPS-exposed lambs during and immediately after open ETT suction. This was probably caused by a reduction in positive end-expiratory pressure during ETT suction, which may have increased cardiac venous return. In addition, a reduction in positive end-expiratory pressure during ETT suction may increase recruitment of pulmonary arterioles and thus increase left-to-right shunting across the ductus arteriosus in the LPS-exposed lambs, which displayed a higher PVR than controls before ETT suction.

Open ETT suction increases $P_{\mathrm{MPA}}$ in human neonates (26). Our data from preterm lambs are consistent, showing that open ETT suction increased $P_{\text {MPA }}$; however, the increase tended to be greater in LPS-exposed lambs as compared with controls. We have previously demonstrated that $P_{\mathrm{MPA}}$ is increased in LPSexposed preterm lambs as compared with controls, during mechanical ventilation and after alterations in mean airway pressure (2). This is consistent with the increased prevalence of pulmonary hypertension in neonates exposed to intrauterine inflammation before birth (5). The increase in $P_{\mathrm{MPA}}$ observed in our experiment is probably caused by impaired pulmonary vascular development following exposure to intrauterine inflammation, which results in an increase in PVR, as previously described $(2,4,7,8)$.

In this study, ewes did not receive antenatal betamethasone because we were interested in the effects of intrauterine inflammation without the confounding effects of betamethasone. The influence of antenatal steroids on the cardiopulmonary hemodynamic changes caused by intrauterine inflammation during ETT suction is a clinically important area of study that warrants further investigation.

The reduction in preductal oxygen saturation observed during and immediately after open ETT suction was probably caused by a reduction in mean airway pressure that resulted in lung derecruitment. This has been demonstrated previously during open ETT suction in newborn infants (27) and during reduced end-expiratory pressures in mechanically ventilated preterm lambs (22). We found that preductal oxygen saturation was further reduced in LPS-exposed lambs. In sheep, intrauterine inflammation has been demonstrated to impair alveolar development, potentially reducing the surface area available for gas exchange (28). The LPS-induced reduction in pulmonary vascular and alveolar development may further impair gas exchange at the terminal alveoli during lung derecruitment caused by a reduction in mean airway pressure.

An increase in HR during ETT suction, of similar magnitude to that in our study, has previously been reported in the preterm neonate (16). The cause of the increase in HR during ETT suction is postulated to be an autonomic response whereby a reduction in arterial oxygen tension is detected by the medulla, resulting in increased sympathetic efferent activity (16). Open ETT suction may inhibit parasympathetic efferent activity, potentially causing an imbalance in autonomic regulation of HR (16). In our study, although ETT suction caused a greater reduction in preductal oxygen saturation in the LPS-exposed lambs, we did not observe a greater increase in HR.

We observed a rapid reduction in carotid arterial PI and increased carotid blood flow and $P_{\mathrm{BCA}}$ during and immediately after open ETT suction, consistent with increased cerebral blood flow and pressure during ETT suction $(18,19)$, irrespective of prenatal treatment. High cerebral blood flow velocity has been demonstrated as a sensitive predictor of neonatal mortality and poor neurological outcome at $12 \mathrm{mo}$ of age $(29,30)$; thus, the cerebral circulatory consequences of open ETT suction may result in brain injury. ETT suctioning is most frequently performed during the first $72 \mathrm{~h}$ after delivery, with a single infant undergoing as many as six suction procedures during this period (19). Regular and rapid fluctuations in cerebral hemodynamics combined with impaired cerebral autoregulation, which is a common characteristic of preterm neonates, particularly those born weighing $<1,500 \mathrm{~g}(31)$, may contribute to the increased incidence of poor neurological outcome and cerebral injury such as intraventricular hemorrhage in the preterm population (32-34).

In conclusion, we have demonstrated that exposure to intrauterine inflammation impairs cardiopulmonary hemodynamics after preterm birth and exacerbates the cardiopulmonary hemodynamic response to open ETT suction. In addition, we have demonstrated that exposure to intrauterine inflammation causes a greater reduction in preductal oxygenation during ETT suction. Our study confirms the interrelationship between cardiopulmonary and cerebral hemodynamics during open ETT suction. We have demonstrated that rapid alterations in cardiopulmonary hemodynamics during open ETT suction result in rapid changes in cerebral hemodynamics. Regular and rapid alterations in cerebral hemodynamics during the neonatal period may cause damage to the preterm brain.

\section{METHODS}

All procedures were approved by the relevant institutional animal ethics committees. At $112 \pm 1$ (mean \pm SD) days of gestation (term $\sim 147 \mathrm{~d}$ ), aseptic fetal surgery was performed on 10 pregnant ewes under general anesthesia (2\% isoflurane in oxygen; Bomac Animal Health, Hornsby, Australia) as described previously (22). Polyvinyl catheters containing heparinized saline were inserted into the fetal brachiocephalic and main pulmonary artery for subsequent measurement of arterial pressures $\left(P_{\mathrm{BCA}}\right.$ and $P_{\mathrm{MPA}}$, respectively). Flow probes (Transonic Systems, Ithaca, NY) were placed around the left pulmonary artery $(4 \mathrm{~mm})$ and left carotid artery $(3 \mathrm{~mm})$. Ewes were allowed $6 \mathrm{~d}$ to recover from surgery before being randomly allocated to receive an intra-amniotic injection of LPS $(n=6$; Escherichia coli 055:B5, $20 \mathrm{mg}$ solubilized in $4 \mathrm{ml}$ saline; Sigma-Aldrich, Castle Hill, Australia) or saline ( $n=4$; controls; $4 \mathrm{ml}$ ) via an amniotic catheter implanted during surgery. Blood pressures and flows were recorded in real time before, during, and after preterm delivery using Powerlab hardware (ADInstruments, Castle Hill, Australia) and data acquisition software (Labchart Pro, version 7.3.1; ADInstruments). Due to difficulty in maintaining arterial catheter patency, $P_{\mathrm{BCA}}$ was recorded for 5 of 6 LPS-exposed lambs and 4 of 4 controls. $P_{\mathrm{MPA}}^{\mathrm{BCA}}$ was recorded for 3 of 6 LPS-exposed lambs and 4 of 4 controls. 


\section{Preterm Delivery and Mechanical Ventilation}

At $125 \mathrm{~d}$ of gestation, $7 \mathrm{~d}$ after intra-amniotic LPS or saline, ewes were anesthetized, and the lambs were delivered via cesarean section. This age marks the late saccular/early alveolar stage of lung development in sheep, which is comparable to the lungs of a human fetus of 24-26 wk gestational age (35). Lambs were intubated and fitted with a pulse oximeter for preductal measurement of oxyhemoglobin saturation (Masimo, Irvine, CA). Lung liquid was passively drained before the lambs were weighed and dried and transferred to an infant warmer where mechanical ventilation was commenced (Babylog 8000+; Drager, Lubec, Germany). Lambs were ventilated in volumeguarantee mode with a tidal volume of $7.5 \mathrm{ml} / \mathrm{kg}$. The upper limit of peak inspiratory pressure was set to $40 \mathrm{cmH}_{2} \mathrm{O}$ and positive end-expiratory pressure was $4 \mathrm{cmH}_{2} \mathrm{O}$. The fraction of inspired oxygen $\left(\mathrm{FiO}_{2}\right)$ was adjusted to maintain preductal arterial oxyhemoglobin saturation between 85 and 95\%. Anesthesia and analgesia were maintained with continuous infusion of alfaxane $(3 \mathrm{mg} / \mathrm{kg} / \mathrm{min})$ via an umbilical vein catheter inserted immediately after delivery.

\section{ETT Suction}

After 30 min of mechanical ventilation, open ETT suction was performed for $30 \mathrm{~s}$. This involved disconnecting the ETT from the mechanical ventilator and inserting a size- 8 French catheter down the ETT, without passing the tip of the ETT, and applying suction at a pressure of $80-100 \mathrm{cmH}_{2} \mathrm{O}$ while gently withdrawing the suction catheter.

\section{Timing of Measurements}

Physiological measurements were made from periods of the data recording taken $1 \mathrm{~min}$ before beginning ETT suction $(-1)$, immediately after beginning ETT suction (0), immediately before removal of the suction catheter (30), $10 \mathrm{~s}$ after reconnection of the ETT with the mechanical ventilator (40), and $1 \mathrm{~min}$ after reconnecting the ETT to the mechanical ventilator (1.30).

\section{Calculations}

Total PBF was integrated over 10 consecutive cardiac cycles at each time point and the integral of each cycle was multiplied by the corresponding HR and averaged to derive LVO. End-diastolic PBF was calculated from five consecutive cardiac cycles at each time point (22). The $\mathrm{AaDO}_{2}$ was calculated according to the equation:

$$
\mathrm{AaDO}_{2}=\left(P_{\text {barometric }}-P_{\mathrm{H}_{2} \mathrm{O}}\right) \times \mathrm{FiO}_{2}-\left(\mathrm{PaCO}_{2} / 0.93\right)-\mathrm{PaO}_{2}
$$

Where $P_{\text {barometric }}$ is barometric pressure, $P_{\mathrm{H} 2 \mathrm{O}}$ is water vapor pressure at $39^{\circ} \mathrm{C}$, and 0.93 is the respiratory quotient (22). OI was calculated according to the equation:

$$
\mathrm{OI}=\left(\mathrm{FiO}_{2} \times \text { mean airway pressure } / \mathrm{PaO}_{2}\right.
$$

LVO was calculated from measurements of total PBF, assuming that flow in the left pulmonary artery equaled $40 \%$ of total PBF, which is based on the weight difference between the right and left lungs (36). PI in the carotid and pulmonary arteries was calculated according to the equation:

$$
\begin{aligned}
\mathrm{PI}= & \text { (peak systolic blood flow }- \text { minimum diastolic blood flow }) / \\
& \text { mean blood flow }
\end{aligned}
$$

All calculations were performed in Labchart Pro (version 7.3.1; ADInstruments).

\section{Statistical Analysis}

Data are presented as mean \pm SE unless otherwise stated. Statistical analyses were undertaken using Sigmaplot software (v12.0; Systat software, Washington, IL). Before open ETT suction, cardiopulmonary and cerebral hemodynamics were compared between the groups using an unpaired Student's $t$-test (Table 1). Owing to baseline differences between the groups, serial data relating to the effect of ETT suction were expressed as percentage change relative to values before open ETT suction. During ETT suction, a two-way repeatedmeasures ANOVA, with treatment (LPS vs. control) and time as factors, was used for comparisons. A Holm-Sidak post hoc test was used to determine the time points at which differences occurred. $P<0.05$ was considered statistically significant.

\section{ACKNOWLEDGMENTS}

The authors gratefully acknowledge the technical assistance of Alison Moxham, Karyn Rodgers, and Valerie Zahra.

\section{STATEMENT OF FINANCIAL SUPPORT}

This study was supported by a National Heart Foundation of Australia grant in aid (to G.R.P.), an Australian Postgraduate Award (to R.G.), National Health and Medical Research Council of Australia (NHMRC) Career Development Fellowships (to T.J.M.M., 303261, and G.R.P., 1026890), an NHMRC Fellowship (to S.B.H., 545921), a Rebecca L. Cooper Medical Research Fellowship (to G.R.P.), and the Victorian Government's Operational Infrastructure Support Program.

Disclosure: The authors declare no conflict of interest.

\section{REFERENCES}

1. Agrawal V, Hirsch E. Intrauterine infection and preterm labor. Semin Fetal Neonatal Med 2012;17:12-9.

2. Polglase GR, Hooper SB, Gill AW, et al. Intrauterine inflammation causes pulmonary hypertension and cardiovascular sequelae in preterm lambs. J Appl Physiol 2010;108:1757-65.

3. Limperopoulos C, Gauvreau KK, O'Leary H, et al. Cerebral hemodynamic changes during intensive care of preterm infants. Pediatrics 2008;122:e1006-13.

4. Polglase GR, Nitsos I, Baburamani AA, et al. Inflammation in utero exacerbates ventilation-induced brain injury in preterm lambs. J Appl Physiol 2012;112:481-9.

5. Woldesenbet M, Perlman JM. Histologic chorioamnionitis: an occult marker of severe pulmonary hypertension in the term newborn. J Perinatol 2005;25:189-92.

6. Yanowitz TD, Jordan JA, Gilmour CH, et al. Hemodynamic disturbances in premature infants born after chorioamnionitis: association with cord blood cytokine concentrations. Pediatr Res 2002;51:310-6.

7. Kallapur SG, Jobe AH, Ikegami M, Bachurski CJ. Increased IP-10 and MIG expression after intra-amniotic endotoxin in preterm lamb lung. Am J Respir Crit Care Med 2003;167:779-86.

8. Kallapur SG, Bachurski CJ, Le Cras TD, Joshi SN, Ikegami M, Jobe AH Vascular changes after intra-amniotic endotoxin in preterm lamb lungs. Am J Physiol Lung Cell Mol Physiol 2004;287:L1178-85.

9. Shibata M, Parfenova H, Zuckerman SL, Leffler CW. Tumor necrosis factor-alpha induces pial arteriolar dilation in newborn pigs. Brain Res Bull 1996;39:241-7.

10. Yanowitz TD, Baker RW, Roberts JM, Brozanski BS. Low blood pressure among very-low-birth-weight infants with fetal vessel inflammation. J Perinatol 2004;24:299-304.

11. Tureen J. Effect of recombinant human tumor necrosis factor-alpha on cerebral oxygen uptake, cerebrospinal fluid lactate, and cerebral blood flow in the rabbit: role of nitric oxide. J Clin Invest 1995;95:1086-91.

12. Watterberg KL, Demers LM, Scott SM, Murphy S. Chorioamnionitis and early lung inflammation in infants in whom bronchopulmonary dysplasia develops. Pediatrics 1996;97:210-5.

13. Hansen-Pupp I, Hallin AL, Hellström-Westas L, et al. Inflammation at birth is associated with subnormal development in very preterm infants. Pediatr Res 2008;64:183-8.

14. Lahra MM, Jeffery HE. A fetal response to chorioamnionitis is associated with early survival after preterm birth. Am J Obstet Gynecol 2004;190:147-51.

15. Viscardi RM. Perinatal inflammation and lung injury. Semin Fetal Neonatal Med 2012;17:30-5.

16. Bourgault AM, Brown CA, Hains SM, Parlow JL. Effects of endotracheal tube suctioning on arterial oxygen tension and heart rate variability. Biol Res Nurs 2006;7:268-78. 
17. Tingay DG, Copnell B, Mills JF, Morley CJ, Dargaville PA. Effects of open endotracheal suction on lung volume in infants receiving HFOV. Intensive Care Med 2007;33:689-93.

18. Perlman JM, Volpe JJ. Suctioning in the preterm infant: effects on cerebral blood flow velocity, intracranial pressure, and arterial blood pressure. Pediatrics 1983;72:329-34.

19. Kaiser JR, Gauss CH, Williams DK. The effects of closed tracheal suctioning plus volume guarantee on cerebral hemodynamics. J Perinatol 2011;31:671-6.

20. Maggiore SM, Lellouche F, Pigeot J, et al. Prevention of endotracheal suctioning-induced alveolar derecruitment in acute lung injury. Am J Respir Crit Care Med 2003;167:1215-24.

21. Polglase GR, Hooper SB, Gill AW, et al. Cardiovascular and pulmonary consequences of airway recruitment in preterm lambs. J Appl Physiol 2009;106:1347-55.

22. Polglase GR, Morley CJ, Crossley KJ, et al. Positive end-expiratory pressure differentially alters pulmonary hemodynamics and oxygenation in ventilated, very premature lambs. J Appl Physiol 2005;99:1453-61.

23. Fuhrman BP, Smith-Wright DL, Kulik TJ, Lock JE. Effects of static and fluctuating airway pressure on intact pulmonary circulation. J Appl Physiol 1986;60:114-22.

24. Fuhrman BP, Everitt J, Lock JE. Cardiopulmonary effects of unilateral airway pressure changes in intact infant lambs. J Appl Physiol 1984;56:1439-48.

25. Hooper SB. Role of luminal volume changes in the increase in pulmonary blood flow at birth in sheep. Exp Physiol 1998;83:833-42.

26. Hickey PR, Hansen DD, Wessel DL, Lang P, Jonas RA, Elixson EM. Blunting of stress responses in the pulmonary circulation of infants by fentanyl. Anesth Analg 1985;64:1137-42.

27. Hoellering AB, Copnell B, Dargaville PA, Mills JF, Morley CJ, Tingay DG. Lung volume and cardiorespiratory changes during open and closed endo- tracheal suction in ventilated newborn infants. Arch Dis Child Fetal Neonatal Ed 2008;93:F436-41.

28. Willet KE, Jobe AH, Ikegami M, Newnham J, Brennan S, Sly PD. Antenatal endotoxin and glucocorticoid effects on lung morphometry in preterm lambs. Pediatr Res 2000;48:782-8.

29. Wong FY, Leung TS, Austin T, et al. Impaired autoregulation in preterm infants identified by using spatially resolved spectroscopy. Pediatrics 2008;121:e604-11.

30. Julkunen MK, Uotila J, Eriksson K, Janas M, Luukkaala T, Tammela O. Obstetric parameters and Doppler findings in cerebral circulation as predictors of 1 year neurodevelopmental outcome in asphyxiated infants. J Perinatol 2012;32:631-8.

31. Soul JS, Hammer PE, Tsuji M, et al. Fluctuating pressure-passivity is common in the cerebral circulation of sick premature infants. Pediatr Res 2007;61:467-73.

32. Kaukola T, Herva R, Perhomaa M, et al. Population cohort associating chorioamnionitis, cord inflammatory cytokines and neurologic outcome in very preterm, extremely low birth weight infants. Pediatr Res 2006;59: 478-83.

33. Del Toro J, Louis PT, Goddard-Finegold J. Cerebrovascular regulation and neonatal brain injury. Pediatr Neurol 1991;7:3-12.

34. Lou HC, Lassen NA, Friis-Hansen B. Impaired autoregulation of cerebral blood flow in the distressed newborn infant. J Pediatr 1979;94: $118-21$.

35. Schittny JC, Burri PH. Development and growth of the lung. In: Fishman AP, ed. Fishman's Pulmonary Diseases and Disorders. New York: McGraw Hill, 2008:91-114.

36. Crossley KJ, Allison BJ, Polglase GR, Morley CJ, Davis PG, Hooper SB. Dynamic changes in the direction of blood flow through the ductus arteriosus at birth. J Physiol (Lond) 2009;587(Pt 19):4695-704. 